\title{
Analysis of Southern Taihang Tourism Production and Research on Brand Marketing Strategy based on SWOT and PST
}

\author{
Xu Zhen-tao \\ Henan Normal University, \\ Xinxiang 453007, China
}

\author{
Zhu wei \\ Henan Normal University, \\ Xinxiang 453007, China
}

\begin{abstract}
Under the new normal economic environment, the traditional tourism faces competition, but also new opportunities in the emerging service industry. Thus, to enrich the expanding tourist market is a powerful guarantee of industrial development. Market research is based on binding to the marketing environment analysis to determine the product's marketing strategy in order to better expand the market space. In this paper, SWOT method and PST tourist area on the South Taihang existing tourism products for analysis, several strategies Taihang Xinxiang south of brand marketing.
\end{abstract}

Keywords- SWOT; PST; Brand Marketing; Festival Marketing; Green Marketing

\section{Introduction}

In the southern Taihang Tourist Resort of Xinxiang, there are rich natural resources, cultural resources, and constantly-improved supporting facilities; the tourism products based on "cultural context" and geographical position have been fully excavated and also marketed on the basis of new strategy after the existing tourism products are classified and analyzed, aiming to promote the local economic development. In this paper, new marketing strategy for the southern Taihang Tourist Resort of Xinxiang is analyzed using SWOT (strength, weaknesses, opportunities, and threats) and PST (positioning, segmenting and targeting) according to the common advantages such as local resources, transportation and culture.
2. Analysis on the tourism products in the southern Taihang Tourist Resort

2.1 SW Analysis on tourism products and supporting facilities

\subsubsection{Cultural tourism products}

Xinxiang has a long history, a profound cultural foundation, and many historical sites from ancient to now. For example, the ancient battlefield at Muye chosen by the King $\mathrm{Wu}$ of Zhou Dynasty, Jiang Taigong's fishing site, and Chen Qiaoyi's mutiny site were gathered here. But some cultural landscape developments in this resort are still in the stage of extensive management; scenic spots are scattered; an interaction between scenic spots and tourists is absent; the management is in low level and efficiency; the potential cultural resources are not deeply excavated. As a result, its further development is powerless, and a scale effect will not be formed.

\subsubsection{Red tourism products}

In the southern Taihang area of Xinxiang, typical characters such as Shi Laihe, Zhang Rongsuo, and $\mathrm{Wu}$ Jinyin representing the fighting spirit of the era emerged for special historical reasons, and the places such as Liuzhuang, Tangzhuang, and Huilong where these people used to work gradually develop to be realistic tourism resources and practice education bases as the red tourism rose in the 1990s. However, the modern tourists' enthusiasm for red tourism declines; red tourism products are not standard in the development process, so that a scale effect is not formed, and high-quality tourism products are 
few and affect the popularity of the southern Taihang area.

\subsubsection{Sightseeing products}

Seen from the geological structure, the southern Taihang area of Xinxiang, as a part of Tai-hang Mountains, is very complex in internal structure and peculiar in external scenes after millions of years of geological changes. On the surface, there are many numerous gorges, valleys, cliffs, and springs to reveal now after the external erosion by the Yellow River water and the natural wind; a lot of falls and primeval forests are distributed between different mountain valleys to make up the northern rich natural ecological tourism landscapes. However, in some natural scenic spots, a combination with the local history and culture resources in the development is not stressed, thus making the unique spirit of the scenic spots absent and unable to leave a profound impression in the mind of tourists.

\subsubsection{Ecological leisure tourism products}

As the people's consumption concept is getting mature, ecological leisure tourism becomes a new focus of consumers. There are numerous primitive forests and alpine meadow resources distributed in the southern Taihang Mountains, providing important conditions for the development of ecological holiday products. In the southern Taihang area of Xinxiang, mountains, gorges and valleys emerged naturally; the natural water body and forest plants are not as good as those in the southern ecological tourism in terms of the sensory experience, and their development and utilization values need further demonstration by experts. Moreover, related systems and facilities are necessarily further improved; there is a great space for developing and promoting the ecological leisure tourism products in the southern Taihang area of Xinxiang.

\subsubsection{Increasingly improved public service facilities}

In the southern Taihang area of Xinxiang, located in the north of the Yellow River, multiple small-range economic regions such as
Zhengzhou's one hour economic circle and Xinxiang's one hour economic circle have been formed with a gradual step along with the rapid development of economy, by relying on the regional transportation junction advantage of Zhengzhou where Xinzheng airport, Beijing-Guangzhou high-speed rail and multi-term highways are gathered. Meanwhile, the county government in the southern Taihang area of Xinxiang regards the development of tourism economy as the most important point of the national economic development by combining with the actual local resource advantages, and emphatically provides supports for tourism companies in the planning and investing process. Along with the increase of the investment, infrastructure is in a completely order construction; all sorts of service systems are being improved; through combined development, different regions can interact with each other from all aspects; the food, accommodation, transportation, sightseeing, shopping, and entertainment services in the tourism industry are increasingly improved. Thus, a modern tourist city pattern has been formed. But economic support is absent in the adjustment of the tourism industry structure; the planning and adjustment of the currently-constructed transportation and existing scenic spots affect the accessibility for tourists; the industry association function is not well improved, and the practicability of infrastructure needs to be further mature.

\subsection{OT analysis on tourism market environment}

\subsubsection{Market opportunity analysis (O)}

First, as Henan was conformed to be a large tourism province, tourism as a sunrise industry booms in China, and the development of the tourism in the southern Taihang area of Xinxiang is receiving a good macro-economic environment. The statistical report of the world tourism organization (WTO) in 2014 showed that China's tourism industry is converted from a big 
tourist resources country to a world tourism power along with the peaceful rise of China and the improvement of residents' consumption level. It is predicted that China will become the world's largest outbound traveler as a well-off society is built successfully.

Second, government attaches great importance to the tourism development and provides policy support. In 2005, the industry orientation for the future development of the tourism in this province was discussed from the strategic level and the tourism development direction was clearly determined, when Henan province's tourism meeting was held. In 2012, all the scenic spots in the southern Taihang area of Xinxiang, dominated by Xinxiang government, were integrated; the Overall Plan for the Tourism Development of the Southern Taihang Area and the Suggestions of Xinxiang Municipal Party Committee and Government on Accelerating the Development of Tourism were made and implemented, so as to provide a basis for the regional resources integration and unified planning.

Third, the transportation is convenient and easily accessible; the cooperative foundation is solid. The "village-to-village communication" project proposed in the new rural construction promotes the scenic spots in the Southern Taihang Area to connect with county roads, so the transportation accessibility is good.

\subsubsection{Market threat analysis $(T)$}

First, the competition is intense and the market is restructured. The ultimate goal of scenic spots as management enterprises is the pursuit of commercial interests. In the southern Taihang area, a great competitive relationship still exists in the stage of integration and transition currently. In the face of new market opportunities and market opportunity restructuring, the pressure from the market competition will inevitably increase.

Second, the consumption is rational and the demand is diversified. Along with the popularization of the mobile terminal applications, the channels for tourists to acquire information are diversified and instantaneous. When consumers make a final choice on the consumption, the demand level is improving. Along with the rational and individualized demand changes of the future consumer market, how to meet the consumer demand on the basis of existing facilities and services is a question necessary for the management of the southern Taihang Tourist Resort to think deeply.

Third, the environment is damaged and the supervision is feeble. In the Southern Taihang Tourist Resort in the stage of integration and transition, the development of new scenic spots is deficiently supervised, so that the environment of some attractions is damaged in the process of construction and also forced to be in a state of light pollution.

\subsubsection{PST analysis of the tourism products in the} southern Taihang area

In combination with the tourism products and market environment in the southern Taihang area, it is found that the local tourism resources are with comparatively special characteristics, objectively because the attractiveness of the tourism products to consumers is weak; cultural products, red tourism products, sightseeing products, leisure vacation products, and ecotourism products are only with a directional appeal. As the tourism market demand is constantly changing, the managers of the southern Taihang tourist resort need to carry out a series of differentiated marketing according to the differences of market demands. The first step is to segment the market on the basis of full market research, so as to determine the target market.

By segmenting the market target and basically orienting the recent domestic tourism market, Zhengzhou, Luoyang, Anyang, Jiaozuo, Puyang, Xuchang, Hebi, Kaifeng, and Heze are listed into the primary tourism market; Bozhou, Handan, Linfen, Nanyang, Wuhan, Hefei, Jinan, Xi'an and other provincial capitals are classified into the secondary potential market; domestic cities such 
as Haikou and Beijing and South Korea, Japan and other neighboring countries and regions are incorporated into the tertiary opportunity market.

\section{Study on brand marketing strategy}

\subsection{Mining cultural resources and implementing festival-oriented marketing activities}

The development of tourism products is dependent on the local culture, and the integration of market operation in the development of tourism products is a future direction of tourism development, and therefore, inexhaustible driving force and strong market competitiveness are produced for the tourism development. The historical "cultural context" in the southern Taihang tourist resort is explored and analyzed to connect the local Nuwa culture, loyalty and filial piety culture of Zhou dynasty, romance culture of Wei and Jin dynasties, clothing culture of Han and Tang dynasties, and architectural culture of Ming and Qing dynasties with the related cultural landscapes, from which clear clues are obvious to all and people can get knowledge about the history. In this area, the above cultures are materialized using specific product forms, thus promoting the cultures to be vivid and attract tourists.

\subsection{Keeping up with the trend of the consumption and bringing forth new ideas into green marketing}

Along with the progress of the era, the change of the people's consumption idea is greatly drivena rational, healthy and green consumption idea is advocated by consumers. Today's tourists propose higher and higher requirements for the primordial environment, but are no longer satisfied with sightseeing. The pursuit of the green environment will be the first choice of tourists.

\subsection{Creating a tourism brand featuring magnificent Taihang Mountains and beautiful Xinxiang and carrying out the brand marketing}

Under the new economic condition that the tourism attains a rapid economic development in China, many new commercial tourism activities have been preliminarily formed; China's tourism development has stepped into the era of brand competition. But how to create the tourism brand projects with the special characteristics of the southern Taihang Tourist Resort is an important issue for the related managers to think deeply in the local tourism development.

\subsection{Expanding the destination space and implementing the integrated marketing}

Xinxiang is adjacent to the provincial capital Zhengzhou which is a transport hub in central China and possesses significant advantages in aviation, railway and highway. This geographical advantage can be fully utilized by the southern Taihang Tourist Resort in the overall planning and integration of different tourist destinations; the integration of the resources in this area is classified; the tourism resources affecting factors are re-measured using the factor analysis method, so as to determine the advantageous resource types again. The investigation on the tourists' satisfaction with the destination image is implemented, and then the problems of the scenic spots are analyzed and revised.

\section{Conclusion}

With the link of capital and interests, the rights of the stakeholders are taken into comprehensive consideration; the southern Taihang Tourist Resort centered Xinxiang is promoted as a whole; Zhengzhou is utilized as an information output platform to implement the marketing strategy integrating leisure and recreation. As a result, the comprehensive competitiveness of the southern Taihang Tourist Resort tourism products in 
central China is enhanced and a scale effect is realized.

\section{Acknowledgement}

This paper was a phased result of the Scientific Research Innovation Project of Henan Normal University for Graduate Students in 2015, "Study on Tourist Destination Brand Marketing Strategy - the Southern Taihang Tourist Resort is taken for Example (No.YW201531)".

\section{References}

[1] ZHANG Liyun. Analysis on Tourism Spatial competition and Cross-elasticity [J]. Journal of Geography and the Study, 2009: 54-57.
[2] Xin Xiang's 12th Five-year Tourism Development Plan. www.xxta.gov.cn, 2013-07-19.

[3] Wu Bihu. Regional Tourism Planning Principle $[\mathrm{M}]$. China Tourism Press, 2012:125-128

[4] BAO Jigang, CHU Yifang. Tourism Geography [M]. Higher Education Press. 2014:29-32

[5] Wang Yanyong. Theory and Practice of Regional Tourism Development Rate Study [J]. Journal of Economic Geography, 2013, (2): 64-68

[6] TIAN Li, Yun Hong. Tourism Economics [M]. Beijing: Tsinghua University Press, 2012, (1): 48-53. 